\title{
Active metabolites formed during hepatic first-pass: simulations featuring their contribution to the overall effect in altered liver clearance and drug-drug interactions
}

\author{
Ahmed M Abdelaziz ${ }^{1}$, Mohammad al-Araby ${ }^{1}$, Laila Mahran ${ }^{1}$ and \\ Hilde Spahn-Langguth*2
}

\author{
Address: ${ }^{1}$ Department of Pharmaceutical Chemistry, German University in Cairo, 11835 Cairo, Egypt and ${ }^{2}$ Department of Pharmaceutical \\ Chemistry, Institute of Pharmaceutical Sciences, Karl Franzens University of Graz, 8010 Graz, Austria \\ Email: Hilde Spahn-Langguth* - hilde.spahn-langguth@uni-graz.at \\ * Corresponding author
}

from I5th Scientific Symposium of the Austrian Pharmacological Society (APHAR) Joint meeting with the Hungarian Society of Experimental and Clinical Pharmacology (MFT) and the Slovenian Pharmacological Society (SDF)

Graz, Austria. 19-2I November 2009

Published: 12 November 2009

BMC Pharmacology 2009, 9(Suppl 2):A38 doi:10.1186/147I-2210-9-S2-A38

This abstract is available from: http://www.biomedcentral.com/I47I-22I0/9/S2/A38

(c) 2009 Abdelaziz et al; licensee BioMed Central Ltd.

\section{Background}

Phase I and - occasionally - also phase II metabolites may contribute to the overall effect of a drug. This is not always apparent or revealed, since total concentrations of metabolites may be low in relation to parent drug concentrations. In the case of carvedilol, using a comparison of HPLC and $\beta_{1}$-specific radioligand receptor binding assay (RRA), it was possible to demonstrate that regarding $\beta$ adrenoceptor blockade the effect appears directly linked to the serum compartment, which indicates instantaneous equilibrium between the blood compartment and the biophase, and that oxidative metabolites significantly contribute to the effect, particularly after oral administration. This drug serves as model compound in different approaches for evaluating the role of formation of active metabolites during first-pass when hepatic clearance varies.

\section{Methods}

A kinetic model, which includes the immediate transformation of a fraction of the dose into active metabolites during first-pass through the liver, i.e., before it reaches the systemic circulation (AM-FP model), was found superior to standard models.

\section{Results}

Overall, both systemic and oral clearance values were different for the two carvedilol enantiomers: $27.5 \mathrm{~L} / \mathrm{h}(R)$ and $49.6 \mathrm{~L} / \mathrm{h}(S)$ for i.v. administration, and $11.3 \mathrm{~L} / \mathrm{h}(R)$ and $21.6 \mathrm{~L} / \mathrm{h}(S)$ for p.o. administration. The hepatic extraction ratio was estimated to approximately 0.76 and 0.77 for the $(R)$ - and $(S)$-enantiomer, respectively.

\section{Conclusion}

For carvedilol, the hepatic extraction ratio is considerable, and the oral availability (calculated assuming complete absorption and no intestinal elimination) amounts to 25$35 \%$ for the parent drug due to extensive first-pass metabolism. In spite of their low serum levels, the contribution of the metabolites must not be neglected, especially for oral dosing. Elimination of the parent drug was found to be rate-limiting, i.e., the kinetics of the metabolites is formation-rate-limited, at least in healthy volunteers. The AM-FP model was most suitable, since parent drug and metabolites appear to enter the systemic circulation simultaneously. The new compartmental model is applicable for PK/PD simulation studies including situations where hepatic clearance is affected. It was used to simulate the contribution of active metabolites formed during firstpass to the overall effect, also under conditions of impaired liver function leading to reduced metabolic 
clearance and in case of drug-drug interactions that are hypothesized to induce absorption.

Publish with Bio Med Central and every scientist can read your work free of charge

"BioMed Central will be the most significant development for disseminating the results of biomedical research in our lifetime." Sir Paul Nurse, Cancer Research UK

Your research papers will be:

- available free of charge to the entire biomedical community

- peer reviewed and published immediately upon acceptance

- cited in PubMed and archived on PubMed Central

- yours - you keep the copyright 